\title{
Testing Buddha: Is Acute Desire Associated with Lower Momentary Happiness?
}

\author{
Stephen L. Murphy ${ }^{1}$ D $\cdot$ Yuka Ozaki ${ }^{2} \cdot$ Malte Friese $^{3} \cdot$ Wilhelm Hofmann $^{1}$
}

Accepted: 20 January 2021 / Published online: 12 February 2021

(c) The Author(s) 2021

\begin{abstract}
A central Buddhist claim is that having desires causes suffering. While this tenet draws from the belief that an acute desire state is more momentarily aversive than a no-desire state, the efficacy of this belief has yet to be comprehensively examined. To empirically investigate this claim, we furnished data from two experience sampling studies across USA/Canadian ( $N=101 ; 3224$ observations) and Japanese cultures ( $N=237 ; 8497$ observations). We compared states of acute desire with states of no desire regarding momentary happiness. We then tested, in an additional step, whether acute desires at greater conflict with personal goals were associated with even lower levels of momentary happiness. Findings were consistent across studies, with participants experiencing greater momentary happiness when not experiencing a desire compared to experiencing acute desire. Also, the greater the desire conflicted with important goals the lower the momentary happiness. The present findings support a key basis of the Buddhist belief that having desires causes suffering, showing acute desire states on average to be more aversive than no desire states.
\end{abstract}

Keywords Desire $\cdot$ Temptation $\cdot$ Momentary happiness $\cdot$ Experience sampling $\cdot$ Buddhism

Craving and desire are the cause of all unhappiness.

Everything sooner or later must change, so do not become attached to anything.

(Gautama Buddha).

Many religious traditions maintain that having desires can render it difficult to experience happiness (Webster 2004). However, the problem of having desires is particularly focal within Buddhism, ${ }^{1}$ in that one of the four noble truths set out in Buddhist thought is that having desires represents the root of all suffering (Teasdale and Chaskalson 2011). Given

\footnotetext{
1 The term 'Buddhism' is used here to encompass a wide variety of schools, and thus does not deny significant differences in beliefs across traditions.

Stephen L. Murphy

Stephen.murphy@ruhr-uni-bochum.de

1 Department of Social Psychology, Faculty of Psychology, Ruhr University Bochum, Universitätsstraße 150, 44801 Bochum, Germany

2 Toyo University, Tokyo, Japan

3 Saarland University, Saarbrücken, Germany
} 
the bold nature of this claim it was somewhat unexpected to find that no clear definition of desire exists within Buddhism (Webster 2004). This absence of a clear definition explains the ongoing debates about what Buddhism actually meant with the term 'desire' (e.g., Webster 2004). ${ }^{2}$ Nonetheless, it is evident that 'desire' so referred to in Buddhist texts is highly characteristic of an appetitive desire (Burton, 2010), that is, a "feeling of wanting that propels us to approach and consume objects or otherwise engage in activities that satisfy a need and, in doing so, yield a gain in immediate pleasure or relief from discomfort" (Hofmann and Nordgren 2015, p. 5). For instance, the types of desire Buddhism consistently regards as problematic are those which have a 'grasping' quality (Burton 2010; Webster 2004) — a 'latching on to the object and sticking like glue' (Burton 2010, p. 194), similar to the affective hotness of appetitive desires. The desire for sensual objects or activities are also considered a particularly likely cause of suffering (Burton 2010). In contrast, Buddhism generally regards other cooler wants or intentions, that are less grasping in nature (e.g., the want to attain nibbana) as less problematic. In fact, they are likely beneficial or necessary for experiencing happiness. Accordingly, these cooler wants will not be referred to as 'desires' in this article.

The basis of this tenet that desire lays at the root of suffering is that when desires are not immediately satisfied individuals are likely to recognize a state of deficit or deprivation that is regarded as a major cause of unhappiness (Webster 2004). For instance, desiring designer clothing, delicious food, or an attractive mate, will frequently result in gratification when satisfied. However, because individuals must often endure periods wherein their present state is at least subconsciously regarded as suboptimal (e.g., when the desire for designer clothing remains acute), it is proposed as likely that simply having desires will hinder happiness (Burton 2010). This outcome is believed particularly likely given the frequency in which individuals will experience desires that are not immediately satisfied in typical daily life (Hofmann et al. 2012). Perhaps expectedly, then, some Buddhist traditions regard any lasting sense of happiness to be unlikely amidst the presence of unfulfilled desires (Ricard 2011). These traditions further maintain that individuals seeking happiness will have greater success if they instead opt to extinguish desire (i.e., remove them, so they are not experienced at all). ${ }^{3}$

Prior psychological theorizing acknowledges that experienced desires that are not yet satisfied, and may or may not be subsequently satisfied, may be at least momentarily aversive (Kavanagh et al. 2005). To ensure clarity in the remainder of this article, we will refer to these unsatisfied desires as either a state of want, 'acute desire', or 'desire presence'. ${ }^{4}$ Elaborated Intrusion Theory (EIT; Kavanagh et al. 2005), for instance, maintains that any delay between desire onset and desire satisfaction will, in most cases, be followed by a sense of perceived deprivation. EIT thus proposes desire onset will usually elicit dissatisfaction in instances when the desire is not immediately enacted following its onset. This overarching aversion to a desire's (even briefly) delayed enactment is proposed to manifest irrespective of any gratification that may result from mentally

\footnotetext{
2 Thus, our definition and measurement of desire in this study may not be compatible with all interpretations of this term in Buddhism.

3 Other interpretations of Buddhist texts regard 'extinguishing' of desire to be akin to transforming desires that are more 'grasping' into desires that are less grasping (Webster 2004).

4 These terms also do not refer to present desires which have been satisfied, even partially, and give no indication of whether satisfaction of a desire is probable (e.g., a desire to eat pizza) or improbable (e.g., a desire for a 3-carat diamond ring).
} 
rehearsing what it is like to satisfy the desire (Kavanagh et al. 2005). For instance, desiring and salivating over a delicious freshly baked cookie may well bring pleasure. However, EIT proposes any pleasure is likely to be over-shadowed by the aversive effects of perceived deficit when desire satisfaction is delayed.

Psychological accounts further reason that acute desire, in some instances, causes aversive responses of a particularly potent intensity (e.g., Hofmann et al. 2013; Kavanagh et al. 2005). In particular, considerable dissatisfaction should result when an acute desire stands in conflict with important personal goals (Hofmann et al. 2013). The reason for this effect is that the period in which a conflicting desire (i.e., a desire in conflict with important personal goals) remains acute is often characterised by internal struggle between whether an individual's behaviour should accord with their desire or with their higher order goal (Hofmann and Kotabe 2013). The positive and negative aspects of each behavioral alternative are salient to the individual as is the awareness that one must be sacrificed at the expense of the other. This conflict usually represents an adaptive motivational signal by setting in motion processes of conflict resolution (Saunders et al. 2017). Nonetheless, it is regarded to be an aversive signal in the moment (Inzlicht and Legault 2014), particularly when mental effort is needed to overcome this internal discord (Dreisbach and Fischer 2012; Saunders et al. 2017). As stated, the experience of an acute, but unfulfilled desire is proposed as aversive even in the absence of a goal-desire conflict because it is experienced as a state of deficit or deprivation. Thus, acute desires additionally in conflict with important personal goals are expected to be particularly disagreeable (Hofmann et al. 2013).

Evidence largely supports psychological theory maintaining that acute desires can give rise to an aversive states or a reduction in momentary happiness (Boujbel 2008; Cooney et al. 1987; Kavanagh et al. 2005; Zinser et al. 1992). Nevertheless, for three reasons this evidence linking acute desire states with reduced momentary happiness could be improved. First, past literature showing increased aversion amidst acute desires do so in isolated episodes or domains only (e.g., the aversive experience alcoholics had when presented with their favourite alcoholic drink which they were then not allowed to consume; Cooney et al. 1987). This renders it unknown whether such effects may simply be domain-specific as opposed to domain-general. Second, past research does not provide a general account of whether the presence of acute desire, on the whole (i.e., across the myriad of instances in daily life where desire is and is not present), is associated with reduced momentary happiness or negative affect. Third, the aversive response often identified after transitioning from a state of no desire to a state of acute desire does not give an adequate account of momentary happiness in instances when a 'no desire' state does not immediately precede a state of want. In other words, it remains possible no desire states that do not immediately precede a state of acute desire (not yet examined) may be associated with a different level of momentary happiness relative to no desire states that $d o$ immediately precede acute desire (previously examined; e.g., Cooney et al. 1987).

To be clear, more comprehensive evidence showing acute desire states to be more aversive than no desire states would not provide direct support for the Buddhist tenet that having desires causes suffering. Indeed, Buddhism is primarily concerned with temporallystable representations of happiness rather than its momentary corollary (Ratnam 2003). Nevertheless, it is the Buddhist belief that acute desire states are aversive and highly prevalent in daily life, and that the pleasure from satisfying desires is often fleeting, that underpins its more well-known tenet that having desires will cause suffering more generally. Thus, getting better evidence that acute desire states are relatively more aversive than no desire states would not only provide strong support for psychological theory. It would also 
provide support for a key foundational belief upon which Buddhisms primary tenet regarding more chronic forms of suffering rests.

Given the value of happiness at individual and societal levels (Oishi and Gilbert 2016), the fact that desires are a ubiquitous aspect of the human condition, and the non-trivial regard that desire and happiness has in Buddhism and other religious traditions (e.g., Christianity, Islam), more evidence is needed to support arguments that acute desire states associate with lower momentary happiness than no desire states. Also, while the veracity of this effect may seem intuitive, further empirical enquiry is required given evidence underlines this tenet is nonetheless not assured apriori. For instance, an absence of desire should enhance momentary happiness relative to acute desire. However, it is yet notable that an absence of desire may in some instances reflect a bleak existence (Oishi et al. 2015), and through apathy and amotivation, can be symptomatic of depression (Treadway and Zald 2011). Also, the onset of desire can, prior to any sense of deficit arising, yet promote a potent positive affective response, and may even, in some instances, give rise to a protracted sense of hope at the desire's future satisfaction (Belk et al. 2003). Indeed, consider how unreciprocated attraction for another individual may lead to hope at what nevertheless may be. This evidence confirms it is not clear, apriori, whether this tenet that acute desires are generally more aversive than no desires states actually reflects empirical reality.

\section{Present Studies}

Accordingly, the aim of the present study is to conduct an indirect test of the Buddhist tenet that having desires causes suffering, by examining the efficacy of a key foundation upon which it rests-that individuals will be, on the whole, momentarily happier when not experiencing a desire compared to experiencing an acute desire. In line with what we call the "Buddha Hypothesis" our primary prediction is that, generally, the presence of an unfulfilled desire will associate with lower momentary happiness relative to desire absence. Our reasoning here is that, although desire absence may on occasion be indicative of or accompanied by low momentary happiness (Oishi et al. 2015; Treadway and Zald 2011), on the whole desire absence is expected to be generally indicative of an absence of perceived deprivation, and therefore increased momentary happiness. Furthermore, building on the work on conflict as an aversive signal, conflicting acute desires are likely to prove particularly aversive. Thus, as a secondary focus we will investigate whether acute desires at greater conflict with personal goals are associated with even lower momentary happiness relative to experiencing no desire.

Recall bias represents an obstacle to accurately measuring relevant constructs (Scollon et al. 2009). Thus, the necessary data was furnished from two large experience sampling studies, enabling analyses to be based upon variables approximately measured in real-time and thereby preventing recall biases.

Of note, for the strictest possible test of the Buddha hypothesis regarding the presence of acute desire versus the absence of desire, we only included present desire occurrences for which people indicated that they had not (yet) enacted the desire in question. This addresses not only the above issue of possible recall biases in an optimal manner, but most importantly, allows to exclude possible confounds due to other factors associated with desire enactment, such as positive effects on momentary happiness due to need satisfaction or negative effects due to guilt (in case of conflict; for an in-depth analysis of affective 
consequences of desire enactment, see Hofmann et al. 2013). All data and materials used in the current studies are posted on the Open Science Framework (https://osf.io/zgvq2/).

\section{Study 1}

\subsection{Method}

\subsubsection{Participants}

One hundred and one participants aged between 19 and 62 years $(M=36.12, S D=12.73$; 65 female, 26 male) were included in this study. ${ }^{5}$ Sample-size was determined by trying to recruit as many participants as possible to maximize power. Most participants were Caucasian (72.5\%), with the remaining African American (9.9\%), American Indian or Alaskan Native $(9.9 \%)$, or of a different ethnicity (7.7\%). Ninety-eight percent of participants completed high school; about two thirds (67.1\%) completed college. Participants were recruited via university mailing lists and publicly available websites and asked to participate in research investigating everyday desires. Eligibility criteria included owning a smartphone, being older than 18 years of age, residing in the United States or Canada, and being fluent in English. Participants were compensated with $\$ 5$ for completing an initial intake survey, and an additional $\$ 25$ for responding to at least 35 out of 49 brief mobile surveys. Participants completing at least five mobile phone surveys and reporting at least five desires over the course of the study were included in this study. The study was approved by the university review board. ${ }^{6}$

\subsubsection{Procedure}

Participants were informed about the general purpose of the study (i.e., to examine how people experience and deal with everyday desires) and received an overview of the study, compensation details, and eligibility criteria. After registering for the study, participants completed an intake survey including demographic information and several personality questionnaires not in the current focus (a complete list of measures is available upon request). Importantly, participants were also provided with a definition of what a desire refers to in this study, this definition being in line with an appetitive desire and not other non-grasping wants (e.g., higher order goals). This definition of desire provided to participants may not encapsulate all interpretations of 'desire' within Buddhism. However, it does fit with our view that the types of wants Buddhism typically regards as problematic are appetitive and grasping in nature. This broad strokes definition of desire was also important to facilitate its measurement in this study. The experience sampling phase commenced on the next day and lasted for seven consecutive days. On each day, participants received seven text messages, directing them to a brief mobile survey via an embedded hyperlink (see the following section on the experience sampling procedure). Text messages

\footnotetext{
5 This sample has been used in one prior publication to examine relations between state mindfulness and self-regulation in everyday life (Friese and Hofmann 2016). The hypotheses and analyses in this article have not been presented before.

${ }^{6}$ Due to a technical error, demographic information was recorded for only 91 of the 101 participants.
} 
were spread across a 14-h time frame between 8 a.m. and 10 p.m., with one message being sent at a random time within each 2 -h block with the additional constraint that two messages be at least 30 min apart (Hektner et al. 2007). A reminder SMS was sent in case the participant did not respond within $15 \mathrm{~min}$ of the original dispatch. On a small fraction of occasions (3.3\%), participants clicked on a previously used link another time to complete another brief survey. These additional data points were retained for analyses. The median delay between the initial and the subsequent response was $1.39 \mathrm{~h}$. After the mobile phase, participants were thanked and compensated for their efforts.

\subsubsection{Experience-Sampling Procedure and Protocol}

Because this study is exclusively focused on relations between desire (i.e., absence vs. presence), desire conflict, and momentary happiness, here we only briefly summarize the experience sampling protocol from where the data was taken (for more details, see Friese and Hofmann 2016). At the beginning of each mobile survey, participants completed a measure of state mindfulness and indicated whether they were either currently or recently (within the last $30 \mathrm{~min}$ ) experiencing a desire. If they indicated no desire, they were asked for their momentary happiness, and the survey was over. If they indicated that they did experience a current or recent desire, they next indicated the desire domain from a list of 16 provided (i.e., food, non-alcoholic drinks, coffee, alcoholic drinks, sleep/rest, sex, media use, social contact, sport, work, leisure/hobbies, to express my anger, smoking, other substances, hygiene-related, other). They also reported on the desire's strength, to what extent they tried to resist the desire, and whether the desire stood in conflict to other goals. They then indicated the degree to which they had enacted the desire (on a seven-point scale from not at all to totally). Finally, participants were asked about their momentary happiness, and indicated the extent to which they had experienced self-conscious emotions. For the below hypothesis tests, we only included present desire occurrences for which people indicated that they had not (yet) enacted the desire in question (i.e., acute desires).

\subsubsection{Key Measures}

Desire conflict was measured by asking participants how much the acute desire conflicted with other important goals, on a Likert scale ranging from 0 (not at all) to 6 (very much). Desire conflict ratings were subsequently coded to indicate instances of low (0-2), medium (3-4), and high (5-6) conflict. Momentary happiness was measured by asking participants how happy they currently felt, on a Likert scale ranging from -3 (very unhappy) to +3 (very happy).

\subsubsection{Analytic Procedures and Strategy}

All core analyses-except descriptive raw data calculations-were conducted within a multilevel framework with random intercepts and fixed effects using the SPSS MIXED procedure for multilevel regression models in order to estimate indirect effects properly. This procedure was conducted using the SPSS syntax functionality with code and instructions made available on OSF to enable the replication of our findings. Given the expected dependency of proposed effects on level 2 units (i.e., observations within participants are expected to be correlated), a multilevel approach should elicit more accurate standard errors and reduced type-1 error rates compared to standard regression (Hox et al. 2010). 
Denominator degrees of freedom for the test of fixed effects were obtained by the Satterthwaite approximation.

An intercept-only model was initially constructed for momentary happiness (our only dependent variable) to examine the degree of variance at level 1 (within-person) and level 2 (between-person). This model is depicted in Eq. (1):

$$
y_{i j}=\beta_{0}+u_{j}+e_{i j}
$$

where $y_{i j}$ represents momentary happiness for the $i$ th observation in the $j$ th participant, $\beta_{0}$ represents the grand mean for momentary happiness, $u_{j}$ represents the deviation in momentary happiness between the participant mean and the grand mean, and $e_{i j}$ represents the error between the participants momentary happiness value and their overall mean. Then, for main analyses, our categorical predictors were added to this model to estimate average levels of momentary happiness for different types of desire experience. First, we estimated average levels of momentary happiness for acute desire vs. no desire situations. This model is depicted in Eq. (2):

$$
y_{i j}=\beta_{0}+\beta_{1} \mathcal{X}_{i j}+u_{j}+e_{i j}
$$

This equation is identical to Eq. (1), with the exception that $\beta_{0}$ represents mean momentary happiness when there is no desire (reference category), $\beta_{0}+u_{j}$ represents mean momentary happiness for participant $j$ when there is no desire, and the slope $\beta_{1}$ represents the difference in the mean momentary happiness when there is an acute desire (i.e., $\mathcal{X}_{i j}=$ 1) relative to when there is no desire (i.e., $\mathcal{X}_{i j}=0$ ). Second, we estimated average levels of momentary happiness between acute desires at low, medium, and high conflict with important personal goals, and no desire contexts. This model is depicted in Eq. (3):

$$
y_{i j}=\beta_{0}+\beta_{1} \mathcal{X}_{i j}+\beta_{2} \mathcal{X}_{i j}+\beta_{3} \mathcal{X}_{i j}+u_{j}+e_{i j}
$$

This equation is identical to Eq. (2), but with the exception that $\beta_{1} \mathcal{X}_{i j}, \beta_{2} \mathcal{X}_{i j}$, and $\beta_{3} \mathcal{X}_{i j}$, represent acute desires that are, respectively, in low, medium, and high conflict with other personal goals held by the participant.

\subsection{Results}

\subsubsection{Descriptive and Frequency Data}

On average, participants responded to $31.92(N=3224, S D=10.76$, range $=7-49)$ out of a maximum of 49 brief surveys, ${ }^{7}$ for a response rate of $65.14 \%$. In total, participants reported 828 current and 642 recent desires $(25.68 \%$ and $19.91 \%$ of all responses, respectively). Participants reported no desire on 1,734 occasions (53.78\%). Of the current desires in the focus of the present analysis (i.e., recent desires not considered in analyses), 310 had not yet been enacted, and hence were retained as acute desires. Of those, 150 (48.39\%), 65 (20.97\%), and 95 (30.65\%) were in Low, Medium, and High conflict (respectively) with other important personal goals. Data pertaining to desire

\footnotetext{
7 Due to a technical issue, data collection for one participant continued beyond the normal cycle. These responses beyond the normal cycle were excluded from all analyses.
} 


\section{Panel A}
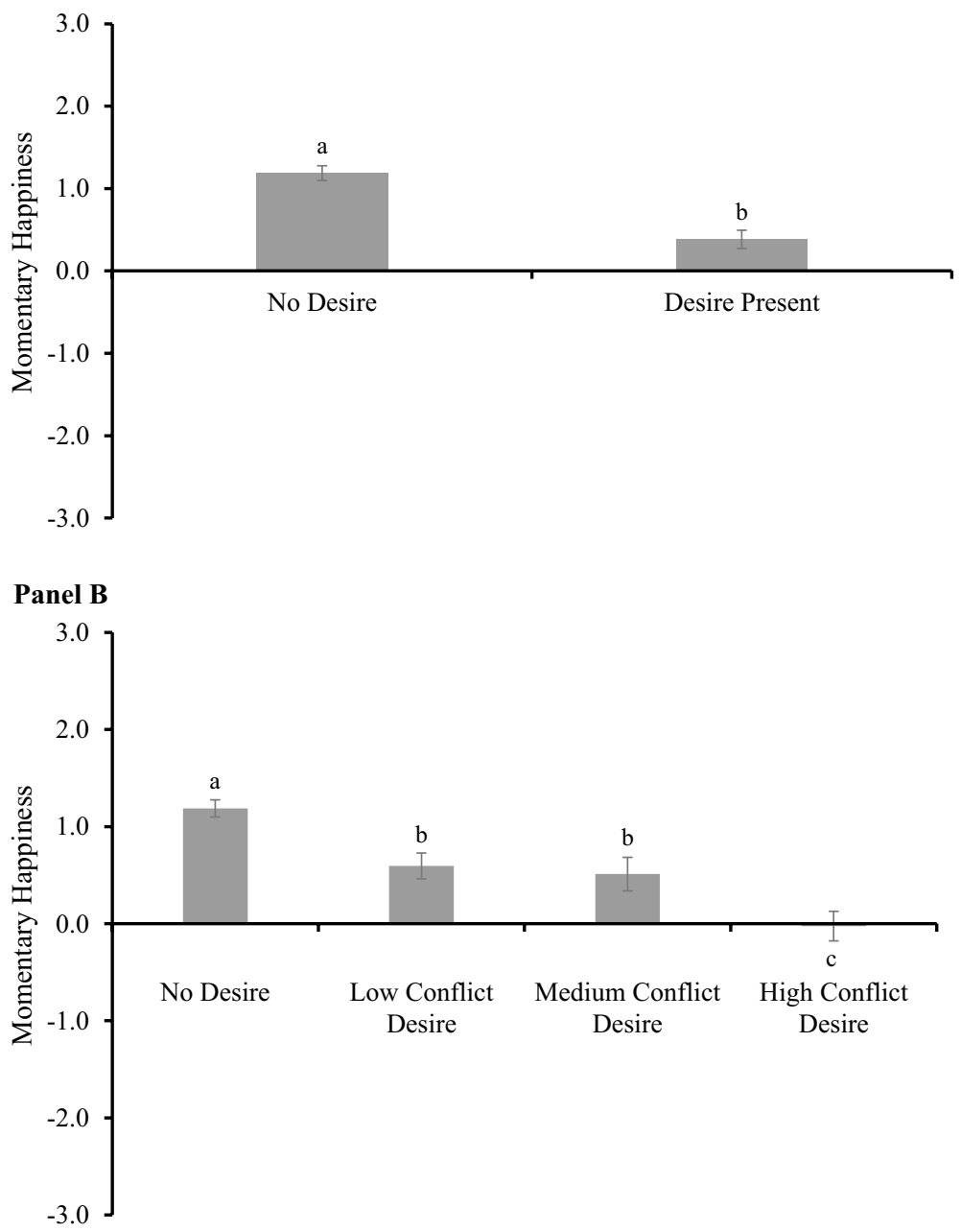

Fig. 1 Momentary happiness ( $-3=$ very unhappy to $+3=$ very happy) in Study 1 when no desire was present, relative to when an acute desire was present (Panel A), and relative to acute desires low, medium, and high in conflict with important personal goals (Panel B). Bars with different letters differ significantly from each other. All means are significant at $p<.001$ with the exception of medium versus high-conflict desire $(p=.007)$. Error bars indicate standard errors of the mean

presence was not available on 20 occasions. Mean momentary happiness per participant was $1.08(S D=0.82$, range $=-0.63$ to 2.83$)$.

Our intercept-only model for momentary happiness revealed that $26.67 \%$ of the variance in momentary happiness was at the between-person level [0.61/ $(1.67+0.61)=0.27$ ], with the remaining variance (i.e., $73.33 \%)$ at the within-person level $(1.67 /(1.67+0.61)=0.73)$. This outcome supports our decision to control for level 2 (person-level) effects when examining hypothesized effects. 


\subsubsection{Desire and Momentary Happiness}

Estimated mean momentary happiness levels by desire type are reported in Fig. 1. As expected, momentary happiness was significantly greater in instances where individuals were not experiencing a desire, compared to when they were experiencing an acute desire $\left(b=0.80\right.$ [Cohens $d=0.62$ medium effect], ${ }^{8} 95 \%$ confidence interval [CI: 0.64, 0.96], $S E=0.08), t(2015.95)=9.88, p<0.001, N_{\text {level } 1}=2037, N_{\text {level } 2}=101$. Furthermore, level of conflict exerted a main effect on momentary happiness, $F(3,1993.03)=31.38, p<0.001$, $N_{\text {levell }}=2037, N_{\text {level } 2}=101$, suggesting that the above lower momentary happiness associated with the degree of conflict with other important goals.

Specifically, momentary happiness when not experiencing a desire (baseline) was significantly greater than when an acute desire was experienced that was at low conflict $(b=0.59$ $[d=0.38$, medium effect], 95\% confidence interval [CI: $0.38,0.81], S E=0.11$, contrast with baseline: $t(2009.03)=5.40, p<0.001)$, medium conflict $(b=0.68[d=0.63$, mediumto-large effect], 95\% confidence interval [CI: 0.37, 0.98], $S E=0.16, t(1979.48)=4.34$, $p<0.001$ ), or high conflict $(b=1.21[d=0.99$, large effect], 95\% confidence interval [CI: $0.95,1.47], S E=0.13, t(1995.37)=9.14, p<0.001)$.

\subsection{Brief Discussion}

Study 1 provided initial support for the Buddha Hypothesis, with momentary happiness greater in the absence of desire than when experiencing an acute desire. This difference in momentary happiness was quite substantial, and likely indicative of the potent nature of negative affective signals (relative to positive affective signals) when acute desire is experienced (e.g., Kavanagh et al. 2005). Our secondary hypothesis that desire-goal conflict would qualify the negative effect of experiencing desire on momentary happiness was also supported: The greater the experienced conflict the stronger the negative effect of experiencing a desire on momentary happiness. This test was informative, as it is in principle possible that acute desires are typically in high conflict with personal goals. This was not the case; there were substantial proportions of low-conflict and medium-conflict desires. In addition, even acute desires in low conflict with personal goals were still associated with significantly lower momentary happiness as compared to no desire states. We therefore believe it is best to conceptualize conflict as an additional source of negativity, next to the state of wanting per se.

\section{Study 2}

In line with the Buddha Hypothesis, Study 1 found that momentary happiness was greater when no desire was experienced compared to when an acute desire was experienced. Furthermore, lower levels of momentary happiness were qualified by the extent to which desires were of a conflicting nature. Stronger experienced conflicts were associated with

\footnotetext{
${ }_{8}$ As in previous research (Hofmann et al. 2014), Cohen's $d$ was computed as a pseudo Cohen's $d$ in the multilevel context, by using the overall means, standard deviations, and cell sizes for the no desire and acute desire categories.
} 
more strongly reduced momentary happiness compared to baseline levels when no desire was experienced.

The primary goal of Study 2 was to replicate these findings in another cultural context, Japan. This replication effort should help strengthen overall conclusions and reduce concerns that the identified effects may be culturally specific. As in Study 1, it was examined whether the extent to which acute desires conflicted with personal goals moderated or qualified effects on momentary happiness. We analyzed data furnished from another experience sampling study measuring identical variables to Study 1 .

\subsection{Method}

\subsubsection{Participants}

Two hundred and thirty-seven participants aged between 18 and $69(M=30.12, S D=14.80$; 132 female, 97 male, 8 unknown) were included in this study. ${ }^{9}$ Sample-size was determined by trying to recruit as many participants as possible to maximize power. Most participants were university students (55.7\%); these students majored in business $(14.8 \%)$, law $(8.9 \%)$, economics $(6.3 \%)$, sociology (3.4\%), and miscellaneous subjects $(22.3 \%)$. The remainder of the sample (44.3\%) were non-students from a range of professions and backgrounds; $28.3 \%$ were employed in full or part-time work, and $16 \%$ were unemployed. This study was approved by the review board of two Japanese universities.

\subsubsection{Procedure}

Prior to the experiencing sampling period participants were informed of the study purpose, provided informed consent, received relevant instructions to enable completion of the experience sampling phase, and were informed about compensation for involvement. Participants also reported their age and gender and completed measures of dispositional variables.

In the experience sampling period participants were randomly signaled (i.e., emailed) seven times daily for seven consecutive days between 9 a.m. and 9 p.m., with each email containing a web link to the online survey. An online scheduling protocol ensured that there was at least a 30 min gap between signals sent to participants. In each email, participants were informed to complete each survey as soon as possible, but at the latest within $2 \mathrm{~h}$ of receiving the signal. Participants were also sent a reminder email $15 \mathrm{~min}$ after the initial signal to facilitate compliance. Participants received the Japanese equivalent of 4.5 USD (i.e., $550 \mathrm{JPY}$ ) for attending the initial session, and 0.4 USD for each experience sampling survey completed (up to a maximum approximately equivalent to $25 \mathrm{USD}$ ). After the experience sampling phase, participants were debriefed, compensated, and thanked for their participation.

\subsubsection{Experience-Sampling Procedure and Protocol}

Because this study is exclusively focused on relations between desire (i.e., absence vs. presence), desire conflict, and momentary happiness, here we only briefly summarize the

\footnotetext{
9 This sample has been used in one prior publication to examine the role of desire-goal conflict in triggering counteractive control (Ozaki et al. 2017).
} 
experience sampling protocol from where the data was taken (for more details, see Ozaki et al. 2017). At the beginning of each mobile survey participants were asked to indicate if they were either currently experiencing a desire or whether they had been experiencing a desire within the last $30 \mathrm{~min}$. If they indicated no desire, they reported their momentary happiness (and questions unrelated to this study) and then the survey was over. If participants reported experiencing a current or recent desire, they next indicated the desire domain from a list of 16 provided (see Study 1 for complete list of these domains). They then reported on the desire's strength, to what extent they tried to resist the desire, whether the desire stood in conflict with other important personal goals, and (if desire-goal conflict did exist) the goals subjective value. They then indicated the degree to which they had enacted the desire (scale identical to Study 1). Due to a technical error, there are 41 instances in which the question about degree of enactment was not presented to participants (and was therefore not completed). Finally, participants were asked about their momentary happiness. As in Study 1, for the below hypothesis tests we only included present desire occurrences for which participants indicated that they had not (yet) enacted the desire in question (i.e., acute desires).

\subsubsection{Key Measures}

Measurement of desire conflict was the same as Study 1, but with a Likert scale ranging from 0 (no conflict at all) to 6 (very high conflict). Coding of desire conflict into Low, Medium, and High, and measurement of momentary happiness, was identical to Study 1.

\subsubsection{Analytic Procedures and Strategy}

All analytic procedures and strategy were identical to Study 1.

\subsection{Results}

\subsubsection{Descriptive and Frequency Data}

On average, participants responded to $35.85(N=8,497, S D=12.16$, range $=1-49)$ out of a maximum of 49 brief surveys, for a response rate of $73.17 \%$. In total, participants reported 1984 current desires and 1,093 recent desires $(23.35 \%$ and $12.86 \%$ of all responses, respectively). Participants reported no desire on 5420 occasions $(63.79 \%)$. Of the current desires in the focus of the present analysis (i.e., recent desires not considered in analyses), 652 had not yet been enacted, and hence were retained as acute desires. Of those, 279 (42.79\%), 194 (29.75\%), and 177 (27.15\%) were in Low, Medium, and High conflict (respectively) with other important personal goals. Mean momentary happiness per participant was 0.65 $(S D=0.80$, range $=-2.23$ to 3.00$)$.

Our intercept-only model for momentary happiness revealed that $30 \%$ of the variance in momentary happiness was at the between-person level $[0.57 /(1.34+0.57)=0.30]$, with the remaining variance (i.e., $70 \%)$ at the within-person level $[1.34 /(1.34+0.57)=0.70]$. This outcome supports our decision to control for level 2 (person-level) effects when examining hypothesized effects. 

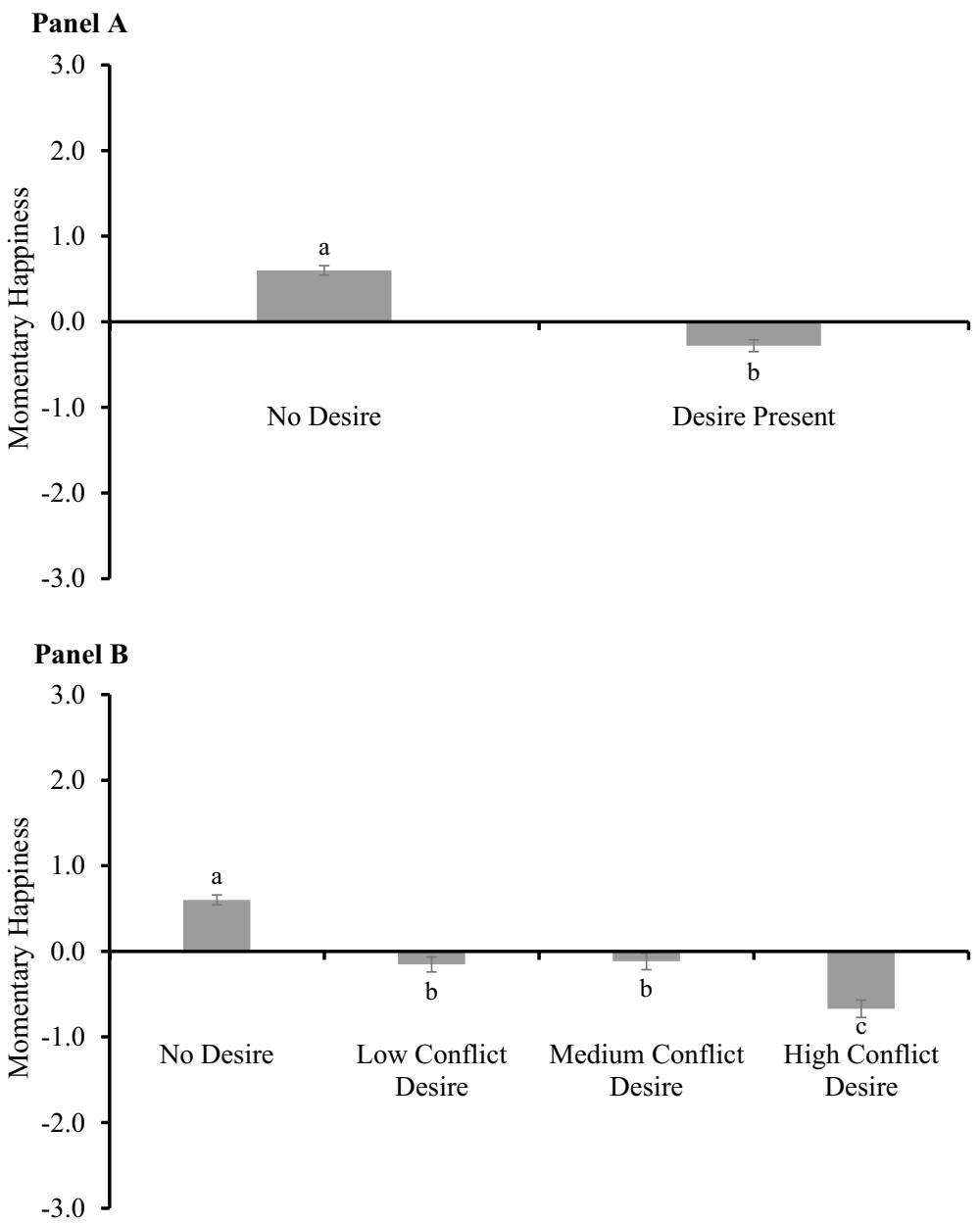

Fig. 2 Momentary happiness ( $-3=$ very unhappy to $+3=$ very happy) in Study 2 when no desire was present, relative to when an acute desire was present (Panel A), and relative to acute desires low, medium, and high in conflict with important personal goals (Panel B). Bars with different letters differ significantly from each other at $p<.001$. Error bars indicate standard errors of the mean

\subsubsection{Desire and Momentary Happiness}

All hypotheses examined are reported in Fig. 2. As expected, momentary happiness was significantly greater in instances where individuals were not experiencing a desire, compared to when they were experiencing an acute desire $(b=0.88[d=0.71$, mediumto-large effect], 95\% confidence interval [CI: 0.78, 0.98], $S E=0.05), t(6012.28)=17.78$, $p<0.001$. Furthermore, level of conflict exerted a main effect on momentary happiness, $F(3,5959.33)=115.57, p<0.001$, suggesting the above reduction in momentary happiness depended on the degree of conflict with other important goals: The stronger the perceived conflict of the desire with personal goals the stronger the reduction in momentary happiness compared to baseline (i.e., no currently experienced desire). 
Specifically, momentary happiness when not experiencing a desire (baseline) was significantly greater than when an acute desire was experienced that was at low conflict $(b=0.75[d=0.66$, medium effect], 95\% confidence interval [CI: 0.61, 0.89], $S E=0.07$, contrast with baseline: $t(5979.19)=10.61, p<0.001$, medium conflict $(b=0.72[d=0.62$, medium effect], 95\% confidence interval [CI: 0.56, 0.88], $S E=0.08), t(5931.11)=8.78$, $p<0.001$, and high $(b=1.27[d=0.89$, large effect], 95\% confidence interval [CI: 1.10 , 1.44], $S E=0.09), t(5988.71)=14.42, p<0.001$, conflict with important personal goals.

\subsection{Brief Discussion}

As in Study 1, Study 2 supported the Buddha Hypothesis-momentary happiness was greater in the absence of desire than when experiencing an acute desire. This replication effort bolsters support for Buddhist proposals that being in a state of want is associated with reduced momentary happiness. This support is particularly clear given participants were of a different cultural background to those in Study 1, thus discounting arguments effects may have been culturally specific. The effect size was also comparable with that in Study $1\left(d_{\text {Study } 1}=0.62, d_{\text {Study2 }}=0.71\right)$. Concerning our secondary hypothesis, effects in Study 2 also replicated those from Study 1: desires at greater conflict with personal goals were associated with the lowest levels of momentary happiness.

\section{General Discussion}

Buddhism claims that having desires is the root of all suffering (Burton 2010). Nonetheless, a key foundation of this popular tenet had yet to be comprehensively examinedthat individuals are, on the whole, momentarily happier when not experiencing a desire compared to when they are experiencing an acute desire. Across two culturally-divergent experience-sampling studies, and in support of our 'Buddha hypothesis', findings aligned with Buddhist tenets in showing momentary happiness was indeed greater when individuals were without desire compared to when they were experiencing an acute desire. Finegrained analyses revealed that acute desires in greater conflict with important personal goals were associated with lower momentary happiness.

The present study investigated whether acute desire states were associated with lower momentary happiness relative to desire states given this theorized effect had yet to be comprehensively tested (Cooney et al. 1987; Kavanagh et al. 2005). Finding support for this effect was also valuable given the notion that acute desire states are aversive relative to no desire states is a foundational Buddhist belief that underpins their more popular tenet that having desires causes suffering. The present study's findings perfectly aligned with this 'Buddha Hypothesis' that acute desire states would be more aversive than no desire states. Importantly, these findings build upon the weaknesses of past research that generally show acute desire states can be aversive (e.g., Cooney et al. 1987; Kavanagh et al. 2005). The present study showed that acute desire states were on average more aversive than no desire states. While unknown whether having desires is associated with lower temporally-stable forms of happiness, the present findings add some weight by supporting the efficacy of key belief upon which this view is based (although it should be borne in mind that pleasure from satisfying desires may yet attenuate, extinguish, or even crowd out the affective consequences of acute desire states). The present findings also keep desire-related research in 
the spotlight (e.g., Hofmann et al. 2012), highlighting that greater consideration of desire states may be critical for better understanding important processes and outcomes.

This research has various strengths, not least that identified effects were replicated and found to be of a similar magnitude across studies $\left(d_{\text {Study } 1}=0.62, d_{\text {Study2 }}=0.71\right)$. That our findings were based upon data drawn from American/Canadian as well as Japanese participants also reduces (although does not eliminate) concerns that the identified effects were culturally specific. For instance, clear cultural differences in mean momentary happiness existed between Study 1 and Study 2. This finding corresponds with divergence in World Happiness Rankings between these nations (Japan, America, and Canada are placed 58th, 19th, and 9th, respectively, where higher rankings reflect happier nations; Helliwell et al. 2019). Nonetheless, we found momentary happiness was similarly reduced across studies when desires were acute rather than absent. A further strength of the present findings is that they came from data gathered at random times seven times a day during all typical waking hours, on all weekdays, in a large participant group, and across a large (unrestricted) number of desire-related domains. Ecological validity in this study was thus high. Indeed, it was the ecologically valid nature of this data, and the need for any strong test of the 'Buddha Hypothesis' to be based upon ecologically valid data, that motivated the present research.

Another strength of the present research was evidence highlighting differences in momentary happiness did not manifest due to a relatively high prevalence of acute desires in high- rather than low-conflict with important personal goals (i.e., across studies lowconflict acute desires were more frequently experienced). This potential explanation for reported differences inexplicably arises given that theory and literature suggest that conflicting (rather than unconflicting) desires require more effort and are generally more aversive (Dreisbach and Fischer 2012; Saunders et al. 2017). Nonetheless, in both studies, lowconflict (acute) desires were more prevalent than medium- or high-conflict desires, and low-conflict desires were also associated with less momentary happiness relative to having no desire. Finally, we did not hypothesize a magnitude for the proposed effects. Irrespective, our findings were consistent with both religious and psychological accounts that effects between desire and no desire are unlikely to be minor (e.g., Kavanagh et al. 2005). Specifically, the identified medium effect across Study 1 and Study 2 in unstandardized metric equated to a nearly 1-point difference on a 7-point scale.

Nonetheless, it is also important to bring attention to a key alternative explanation for our findings. That is, although conceived, in line with Buddhist tenets, that an acute desire state would reduce momentary happiness relative to a no desire state, it yet remains possible this identified effect reflected (at least in part) the reverse causal sequence - that lower (higher) momentary happiness gave rise to an acute (no) desire state. Indeed, this causal direction is equally conducive as it's opposite with the present findings. Furthermore, this reverse causal sequence has theoretical and empirical support-aversive states like stress, fatigue, and emotional distress are well acknowledged to orient individuals towards more immediately gratifying opportunities (Tice et al. 2001). Accordingly, although considerable support exists to suggest acute desire promotes an aversive state (Kavanagh et al. 2005), that the present study was methodologically constrained in its ability to make strong causal claims demands the veracity of the reverse causal sequence should not be overlooked.

A secondary aim of the present study was to examine whether (acute) desires in greater conflict with important personal goals would, overall, be associated with lower levels of momentary happiness relative to having no desire. We hypothesized that momentary happiness would be lower, relative to the no desire state, when the degree of conflict with important goals was higher. Parts of this effect were established 
previously in a different sample, but without a more fine-grained analysis of degree of conflict, and without the crucial no desire baseline (Hofmann et al. 2013). Findings across both studies reported here provided a more generalizable basis for this claim, showing greater momentary happiness when conflict with personal goals was low or medium rather than high, and that even low conflict states were still experienced as lower in momentary happiness than no desire states.

\subsection{Limitations}

A first limitation of the present findings has been highlighted - that causality cannot be inferred in the present correlational research. Therefore, caution is warranted in concluding that desire-related variables (e.g., acute vs. no desire; low vs. high conflict) may have caused differences in momentary happiness. For instance, it is possible participants, in moments they were less (more) momentarily happy, were more likely to have (no) desires. This limitation can be remedied in future laboratory-based settings or in research using ecological momentary interventions (e.g., Heron and Smyth 2010).

A second limitation is given by the relatively low number of acute desire experiences utilized for the present purpose. These relatively low numbers prevented exploratory analyses of interest-e.g., to examine whether the domain in which acute desires arose moderated the extent to which level of conflict with other personal goals associated with momentary happiness. However, the decision to not include satisfied desire experiences in our analyses was an important one to prevent confounding effects. Despite the low number of cases, results across the two studies appeared quite robust and replicated well in the two different cultural settings. This provides some confidence in the robustness and generality of findings.

A third limitation is that, although our sample was heterogenous, approximately $78 \%$ of our sample in Study 1 was Caucasion. This renders it unknown whether our results would replicate in a more diverse sample. This argument can be extended to other characteristics. For instance, a high percentage of participants in both samples were college/university educated; much fewer participants exhibited lower educational attainment. Future research should aim to remedy this issue by testing this Buddha Hypothesis using a more diverse sample.

A final limitation is that the data furnished for this study precluded the possibility of examining whether desire-related variables (e.g., acute vs. no desire; low vs. high conflict) associated with more temporally-stable representations of happiness (momentary representations of happiness were available only). While the high frequency in which acute desires are experienced in typical daily life suggests momentary decrements in happiness may hinder broader representations of happiness (e.g., life satisfaction, wellbeing), this transfer effect was not examined and thus is not supported. Buddhist tenets primarily concern the chronic rather than acute effects of desire-related instances (i.e., how desire influences happiness in general rather than in momentary instances). Future research should therefore aim to explicitly measure more temporally-stable representations of happiness to ensure a more robust test of Buddhist arguments.

\subsection{Conclusion}

Buddhism argues individuals should extinguish desire to enhance happiness, but the underlying basis of this claim, that acute desires states are more aversive than no desire 
states, has yet to be comprehensively supported. The present study provides support for the 'Buddha Hypothesis' that acute desire states associate with lower momentary happiness than no desire states, and informs the scientific literature of critical factors underlying momentary happiness. The size of differences in momentary happiness was not marginal and was substantial when a state of want conflicted highly with other important personal goals.

Authors' contribution W.H. conceived of the present research idea. S.L.M, W.H., and Y.O developed the hypotheses. S.L.M and W.H. conducted the data analyses. S.L.M. wrote the initial draft with support from W.H. All authors provided critical feedback and contributed substantially to the final version of the manuscript.

Funding Open Access funding enabled and organized by Projekt DEAL.

Availability of Data and Material Study data is available at the following link: https://osf.io/zgvq2/.

Code Availability Study code for conducting relevant analyses is available at the following link: https://osf. io/zgvq2/.

Open Access This article is licensed under a Creative Commons Attribution 4.0 International License, which permits use, sharing, adaptation, distribution and reproduction in any medium or format, as long as you give appropriate credit to the original author(s) and the source, provide a link to the Creative Commons licence, and indicate if changes were made. The images or other third party material in this article are included in the article's Creative Commons licence, unless indicated otherwise in a credit line to the material. If material is not included in the article's Creative Commons licence and your intended use is not permitted by statutory regulation or exceeds the permitted use, you will need to obtain permission directly from the copyright holder. To view a copy of this licence, visit http://creativecommons.org/licenses/by/4.0/.

\section{References}

Belk, R. W., Ger, G., \& Askegaard, S. (2003). The fire of desire: A multisited inquiry into consumer passion. Journal of Consumer Research, 30, 326-351. https://doi.org/10.1086/378613.

Boujbel, L. (2008). Never-ending desires: Assessing consumers' propensity to desire consumption objects. European advances in Consumer Research, 8, 319-324. Retrieved from: http://www.acrwe bsite.org/volumes/13860/eacr/vol8/E-08

Burton, D. (2010). Curing diseases of belief and desire: Buddhist philosophical therapy. Royal Institute of Philosophy Supplements, 66, 187-217. https://doi.org/10.1017/S1358246109990312.

Cooney, N. L., Gillespie, R. A., Baker, L. H., \& Kaplan, R. F. (1987). Cognitive changes after alcohol cue exposure. Journal of Consulting and Clinical Psychology, 55, 150-155. https://doi. org/10.1037/0022-006X.55.2.150.

Dreisbach, G., \& Fischer, R. (2012). Conflicts as aversive signals. Brain and Cognition, 78, 94-98. https ://doi.org/10.1016/j.bandc.2011.12.003.

Friese, M., \& Hofmann, W. (2016). State mindfulness, self-regulation, and emotional experience in everyday life. Motivation Science, 2, 1-14. https://doi.org/10.1037/mot0000027.

Hektner, J. M., Schmidt, J. A., \& Csikszentmihalyi, M. (2007). Experience sampling method: Measuring the quality of everyday life. Sage. Retrieved from: https://books.google.co.uk/ books?hl=en \&lr=\&id=05e5d_KBYY0C\&oi=fnd\&pg =PP13\&dq=Hektner, +J.+M., +Schmi $\mathrm{dt},+\mathrm{J} .+\mathrm{A} .,+\% 26+$ Csikszentmihalyi\&ots=rtMLQ3pfa1 \&sig=S6sd4CKSkBi3-Q4crIsKDhy QXtc\#v=onepage\&q=Hektner\%2C\%20J.\%20M.\%2C\%20Schmidt\%2C\%20J.\%20A.\%2C\%20 $\% 26 \% 20$ Csikszentmihalyi\&f=false

Helliwell, J. F., Layard, R., \& Sachs, J. D. (2019). World happiness report 2019. New York: Sustainable development solutions network. Retrieved from: https://worldhappiness.report/ed/2019/ 
Heron, K. E., \& Smyth, J. M. (2010). Ecological momentary interventions: Incorporating mobile technology into psychosocial and health behaviour treatments. British Journal of Health Psychology, 15, 1-39. https://doi.org/10.1348/135910709X466063.

Hofmann, W., Baumeister, R. F., Förster, G., \& Vohs, K. D. (2012). Everyday temptations: An experience sampling study of desire, conflict, and self-control. Journal of Personality and Social Psychology, 102, 1318-1335. https://doi.org/10.1037/a0026545.

Hofmann, W., Kotabe, H., \& Luhmann, M. (2013). The spoiled pleasure of giving in to temptation. Motivation and Emotion, 37, 733-742. https://doi.org/10.1007/s11031-013-9355-4.

Hofmann, W., \& Kotabe, H. P. (2013). Desire and desire regulation: Basic processes and individual differences. In J. J. Gross (Ed.), Handbook of emotion regulation (2nd ed., pp. 346-360). New York: Guilford. Retrieved from: https://psycnet.apa.org/record/2013-44085-021

Hofmann, W., \& Nordgren, L. F. (2015). Introduction to the psychology of desire. In W. Hofmann \& L. F. Nordgren (Eds.), The psychology of desire (pp. 1-16). New York: Guilford. Retrieved from: https ://psycnet.apa.org/record/2015-32212-000

Hofmann, W., \& Van Dillen, L. (2012). Desire: The new hot spot in self-control research. Current Directions in Psychological Science, 21, 317-322. https://doi.org/10.1177/0963721412453587.

Hofmann, W., Wisneski, D. C., Brandt, M. J., \& Skitka, L. J. (2014). Morality in everyday life. Science, 345(6202), 1340-1343. https://doi.org/10.1126/science.1251560.

Hox, J. J., Moerbeek, M., \& Van de Schoot, R. (2010). Multilevel analysis: Techniques and applications. Routledge. Retrieved from: https://books.google.co.uk/books?hl=en\&lr=\&id=yElZBwAAQB AJ\&oi=fnd\&pg =PP1\&dq=hox +multilevel+modeling\&ots=G_hLcMNkN5\&sig=hd9cNEefJ5 EgmYDRzMwVVh8VMUs\#v=onepage \&q=hox $\% 20$ multilevel $\% 20$ modeling $\& \mathrm{f}=$ false

Inzlicht, M., \& Legault, L. (2014). No pain, no gain: How distress underlies effective self-control (and unites diverse social psychological phenomena). The control Within: Motivation and its regulation, 115-132. Retrieved from: http://www.sydneysymposium.unsw.edu.au/2013/chapters/InzlichtSS SP2013.pdf

Kavanagh, D. J., Andrade, J., \& May, J. (2005). Imaginary relish and exquisite torture: The Elaborated Intrusion theory of desire. Psychological Review, 112, 446-467. https://doi. org/10.1037/0033-295X.112.2.446.

Oishi, S., \& Gilbert, E. A. (2016). Current and future directions in culture and happiness research. Current Opinion in Psychology, 8, 54-58. https://doi.org/10.1016/j.copsyc.2015.10.005.

Oishi, S., Westgate, E., Tucker, J., Komiya, A., Hofmann, W., \& Nordgren, L. (2015). Desires and happiness: Aristotelian, Puritan, and Buddhist approaches. The Psychology of Desire, 286-306. Retrieved from: https://www.erinwestgate.com/uploads/7/6/4/1/7641726/oishi_westgate_tucker komiya_2014_desire_chapter_finalversion.pdf

Ozaki, Y., Goto, T., Kobayashi, M., \& Hofmann, W. (2017). Counteractive control over temptations: Promoting resistance through enhanced perception of conflict and goal value. Self and Identity, 16, 439459. https://doi.org/10.1080/15298868.2016.1269668.

Ratnam, M. V. R. K. (2003). Dukkha: suffering in early Buddhism. Discovery Publishing House. Retrieved from: https://books.google.co.uk/books?hl=en\&lr=\&id=y6TUD2nUBD $\mathrm{gC} \& \mathrm{oi}=$ fnd $\& \mathrm{pg}=\mathrm{PP} 14 \& \mathrm{dq}=$ buddhism + dukkha\&ots $=2 \mathrm{KxFh}-\mathrm{fzlT} \& \operatorname{sig}=\mathrm{TVuyk} 1 \mathrm{IccZTRsd} 1$ DANjY_qw4AZo\#v=onepage \&q=buddhism\%20dukkha\&f $=$ false

Ricard, M. (2011). The Dalai Lama: Happiness through wisdom and compassion. International Journal of Wellbeing, 1, 274-290. https://doi.org/10.5502/ijw.v1i2.9.

Saunders, B., Lin, H., Milyavskaya, M., \& Inzlicht, M. (2017). The emotive nature of conflict monitoring in the medial prefrontal cortex. International Journal of Psychophysiology, 119, 31-40. https:// doi.org/10.1016/j.ijpsycho.2017.01.004.

Scollon, C. N., Prieto, C. K., \& Diener, E. (2009). Experience sampling: Promises and pitfalls, strength and weaknesses. In Assessing well-being (pp. 157-180). Springer, Dordrecht. doi: https://doi. org/10.1007/978-90-481-2354-4_8

Teasdale, J. D., \& Chaskalson, M. (2011). How does mindfulness transform suffering? I: The nature and origins of dukkha. Contemporary Buddhism, 12, 89-102. https://doi.org/10.1080/14639 947.2011.564824.

Tice, D. M., Bratslavsky, E., \& Baumeister, R. F. (2001). Emotional distress regulation takes precedence over impulse control: If you feel bad, do it! Journal of Personality and Social Psychology, 80, 53-67. https://doi.org/10.1037//0022-3514.80.1.53.

Treadway, M. T., \& Zald, D. H. (2011). Reconsidering anhedonia in depression: lessons from translational neuroscience. Neuroscience \& Biobehavioral Reviews, 35, 537-555. https://doi. org/10.1016/j.neubiorev.2010.06.006. 
Webster, D. (2004). The philosophy of desire in the Buddhist Pali Canon. Routledge. Retrieved from: http://www.chinabuddhismencyclopedia.com/en/images/2/28/The_Philosophy_of_Desire_in_the_ Buddhist_Pali_Canon_-_RoutledgeCurzon.pdf

Zinser, M. C., Baker, T. B., Sherman, J. E., \& Cannon, D. S. (1992). Relation between self-reported affect and drug urges and cravings in continuing and withdrawing smokers. Journal of Abnormal Psychology, 101, 617-629. Retrieved from: https://psycnet.apa.org/buy/1993-15141-001

Publisher's Note Springer Nature remains neutral with regard to jurisdictional claims in published maps and institutional affiliations. 